\title{
The Grinding Wheel Performance in the Transverse Cylindrical Grinding of an Eutetic Alloy
}

\author{
Eduardo Carlos Bianchi ${ }^{\mathrm{a} *}$, Eraldo Jannone da Silva ${ }^{\mathrm{d}}$ \\ Vinicio Lucas Vargas $^{\mathrm{c}}$, Thiago Cardoso Magagnin ${ }^{\mathrm{c}}$, Rodrigo Daun Monici ${ }^{\mathrm{b}}$, \\ Osmar Vicari Filho ${ }^{\mathrm{b}}$, Paulo Roberto de Aguiar $^{\mathrm{a}}$ \\ ${ }^{\text {a }}$ PhD Student, UNESP, Engineering College, Bauru \\ ${ }^{\mathrm{b}}$ M. Sc. in Mechanical Engineering UNESP, Bauru \\ ${ }^{\mathrm{c}}$ Graduating in Mechanical Engineering UNESP, Bauru, \\ PhD. Student at University of São Paulo, São Carlos \\ ${ }^{\mathrm{d}}$ PhD Student
}

Received: September 9, 2001; Revised: July 2, 2002

\begin{abstract}
This paper presents a research in which the performance of two different grinding wheels (a conventional and a CBN wheel) was evaluated in a transverse cylindrical grinding of a eutectic alloy. Three cutting conditions were tested: rough, semi-finishing and finishing. As evaluating parameters, the cutting force, the roughness and the wheel wear were measured. As a result, the best values of the cutting force and the roughness were obtained when grinding with the conventional wheel, due to the best dressing operation performed, for all the cutting conditions. The CBN presented the best $G$ ratio values. Although, the $G$ ratio values observed for the $C B N$ wheel were lower than the expected one due to the non-effective dressing operation applied. In the conditions tested, in terms of cutting force and roughness, the conventional wheel is the best choice. In terms of $\mathrm{G}$ ratio, a cost analysis is crucial to determine if the differences observed among the wheels can justify the use of the $\mathrm{CBN}$ wheel. In a positive case, the dressing operation must be improved.
\end{abstract}

Keywords: grinding, grinding wheel, performance, dressing

\section{Introduction}

The grinding process is one of the most used finishing processes in the manufacture of precision components. Although its technical knowledge is not so widely disclosed as other cutting processes that use tools with definite geometry (turning, drilling, milling, etc). The correct selection of the cutting conditions and the wheel specifications can optimize the arc length of contact, providing a greater material removal possibility (Bianchi, 1992) ${ }^{1}$. The superabrasive wheels are modern tools to grinding hardened steels and their performance is significantly superior to the conventional wheels.

According to Hitchiner (1999) $)^{2}$, within the last two or three years, major changes have begun to occur within the aerospace industry in its application of grinding to processing components made from nickel-based superalloys (Inconel, Udimet, Rene, Waspaloy \& Hastelloy). Many oth- ers industry fields, which require the use of wear and thermal resistant materials mentioned above (automobilist, among others), are looking forward to the improvement in the grinding process. This fact leads to the development of new cutting fluid types and new application methods, the development of improved CBN wheels, new dressing methods and most reliable monitoring systems.

Shifting from conventional wheels to CBN ones in grinding of hardened materials can be a driving factor for increasing the grinding performance and the workpiece integrity. Although, this action implies a number of requirements, which include: high cutting speeds, improved balancing systems, suitable machine stiffness, effective dressing systems, properly cutting fluid application, reliable monitoring systems, among others. These facts permit exploring the best mechanical and thermal proprieties of the CBN grains when compared to the conventional ones. 


\subsection{Objective}

This article presents a research in which the performance of a superabrasive CBN wheel and conventional one in a transerve cylindrical grinding of a superalloy EUTECTIC ECT-NA-4923 was analyzed. Three different grinding conditions (rough, semi-finishing and finishing) were performed and the evaluation parameters for the comparative grinding wheel performance were the specific cutting force, roughness and wheel wear.

\section{High Performance Deep Grinding of Inconel}

According to Tawakoli and Tavakkoli $(1985)^{5}$, Inconel is a kind of material classified as being hard of cutting, due to its extreme toughness. Its grinding causes a hard glazing of the wheel. However, due to its features of thermal stability and mechanical strength, Inconel is widely used in the aeronautic, automobilist and electrical turbine industry.

The grinding process of Inconel has been applied for a time, since the conventional cutting processes (turning, milling, etc) don't seem to be a good solution. They need a high dimensional precision and high cutting capacity for hardned materials.

In that case, the grinding process is distinguished by the continuos dressing, thus making the wheel surface to be continuously renewed (by the dresser) while the cutting process is developing. Without forgetting the tendency of the material to glaze the wheel, this method made possible the grinding to be used for a long time as the cutting process of Inconel. It is an expensive process, so while the wheel is cutting the dresser is wearing it, keeping it sharp and free from the glazing produced by the workpiece material. Besides, the material removal rates are too low, if compared with those achieved by superabrasive wheels and the wheel wear is very intense. The aeronautic and power industries are driving investments to research on the application of superabrasives in the grinding of Inconel.

Using a process named high performance deep grinding (HPDG), that consists on the utilization of highly deep cutting (with slow advance) and high cutting speeds, so producing higher material removal rates, one can reach a profitable cutting performance. High cutting speeds cause the increase of force and cutting power, as well as a great heat generation. This can be reduced by using a high cutting fluid flow rate and adequate pressure, which contributes to the withdrawal of the heat generated in the cutting and to easily remove the chips from the grinding zone.

The tests performed by König, Yegenoglu and Stukenholz (1985) showed that the high cutting velocity of the $\mathrm{CBN}$ wheels allowed to increase twenty times the material removal rate, if compared with the conventional wheels. So, it is possible to achieve a reduction of time and costs involved in the process. The final cost of the conventional grinding system is about $30 \%$ greater if compared with the grinding system with superabrasive CBN wheels. Many developments are expected in the manufacturing technique of CBN wheels, because of the great development of this type of abrasive tool. The authors suggest that a significant increase of the performance in the grinding of DTG (difficult to grinding) materials can be achieved with $\mathrm{CBN}$ wheels, since these ones present resistance to the wear, and a better heat dissipation when compared with conventional wheels of aluminum oxide, leading to decreases in the time of production, without quality loss. The optimization of the truing and dressing that was seen only in the superabrasive CBN wheels is important to adapt the wheel topography to the grinding process requriements.

The wheel dressing is found to be a parameter with a great impact upon the grinding wheel topography and thus upon the heat generation in the cutting process (Brinksmeier et al., 1982). Coarse dressing produces a wheel surface that is open and free cutting. On the other hand, a closed grain structure in the wheel results in wheel surfaces that are not free cutting which leads to an increased thermal impact. Tensile residual stresses increase although the surface quality is improved in most cases. After dressing, CBN grains reveal a finely structured surface with secondary cutting edges. They ensure a good chip formation and enable the cutting fluid to penetrate between the individual edges. So the conditions of lubrication and cooling are improved. $\mathrm{Al}_{2} \mathrm{O}_{3}$ grains, however, show often-flat grain surfaces, which lead to an increase of forces, and thus friction induced heat (Brinskmeier, 1986).

The dressing of conventional and superabrasive wheels is quite different. These differences include the dressing procedures and the fracture mechanism of the grain during dressing. The active surface of the wheel after dressing and its sharpness are strongly dependent on a list of factors, which includes the relation between wheel speed and dresser speed (speed ratio $\mathrm{q}_{\mathrm{d}}$ ), depth of cut per pass, total depth of cut, transverse rate, dresser contact width, among others. A non-effective dressing operation can lead to a decrease in the grinding performance of the wheel, leading to an undesirable results.

\section{Methodology}

The tests were performed in an external cylindrical grinder, using test pieces having their core formed by ABNT 1020 steel, serving as a base to support the superalloy that would be ground. A $4 \mathrm{~mm}$ thick layer of Eutectic ECT-NA4923, 73 HRc, was deposited in the surface of the workpiece using a MIG welding process. This process makes the welded material to present a very high roughness. A previous grinding operation with a conventional wheel was applied in order to correct the geometrical errors of the 
workpiece. The Fig. 1 presents the workpiece ground in the tests.

A transverse grinding operation was applied in the tests. The cutting conditions were classified as rough grinding, semi-finishing grinding and finish grinding. The Fig. 2 presents the grinding kinematics and Table 1 shows a summary of input parameters for the grinding with both conventional and superabrasive wheels.

Two different types of grinding wheels were applied: a conventional one (alumina), 19A100SVSB, and a resin bond superabrasive one $(\mathrm{CBN}), \mathrm{B} 125 \mathrm{R} 100 \mathrm{BK}$. A single-pointdiamond dressing tool was used for dressing the conventional wheel. It was adopted the $\mathrm{U}_{\mathrm{d}}$ (dressing overlapping) value equal to $)=1,\left(\mathrm{U}_{\mathrm{d}}=\mathrm{b}_{\mathrm{d}}(\right.$ dressing tool width $) / \mathrm{s}_{\mathrm{d}}$ (dressing lead) (maximum sharpness) for the rough and semi-finishing operations. An Ud equal to 5 was applied for the finishing operation. A diamond rotary disc was used to the CBN wheel truing. A speed ratio $\mathrm{q}_{\mathrm{d}}$ equal to 0.7 positive was applied. The resin bond wheel was conditioned using an alumina stick. The CBN dressing parameters are the same for all the cutting conditions.

The evaluation parameters for the grinding wheel performance were the specific grinding force the roughness and $\mathrm{G}$ ratio. The Table 2 presents the number of strokes between each roughness measurement.

\section{Results and Discussion}

\subsection{Results of specific cutting force}

The Figs. 3-8 present the results relative to the specific cutting force when grinding with the conventional and the

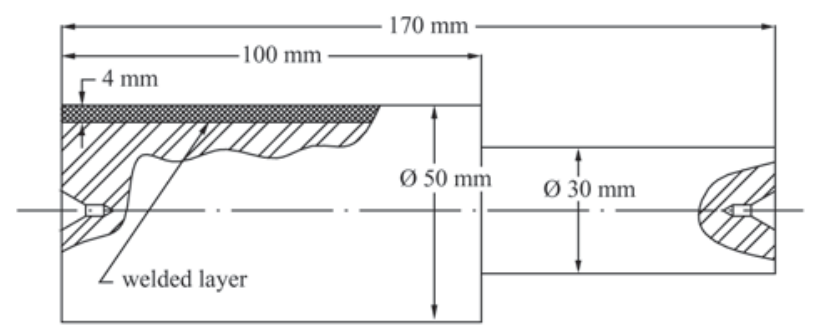

Figure 1. Dimensions of the workpiece used in the tests. superabrasive wheels. In each graph are presented two different curves. The curve "cutting" represents the average value of the specific cutting force for the correspondentgrinding stroke and the curve "spark-out" the residual force during spark-out in the returning transversal movement prior one subsequent stroke. Each point of the curve represents one grinding stroke which is linked with the volume of material which was removed in the stroke.

In the Figs. 3-8 it is possible to observe that increasing the severity of the operation (finishing to rough) there is an

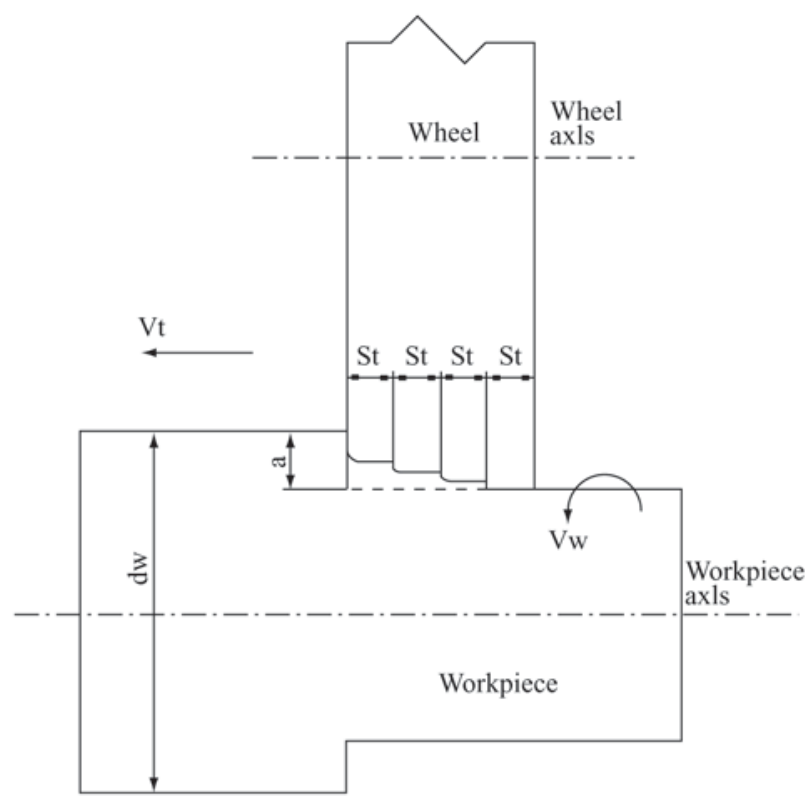

Figure 2. The kinematics of the external cylindrical transverse grinding (Malkin, 1989) ${ }^{4}$.

Table 2. Summary of cutting conditions for the tests.

\begin{tabular}{lcc}
\hline Condition & $\begin{array}{c}\text { Total number } \\
\text { of strokes }\end{array}$ & $\begin{array}{c}\text { Number of strokes } \\
\text { between each roughness } \\
\text { measurement of Ra }\end{array}$ \\
\hline Rough & 17 & 3 \\
Semi-finishing & 33 & 5 \\
Finishing & 102 & 15 \\
\hline
\end{tabular}

Table 1. Summary of cutting conditions for the tests.

\begin{tabular}{lccccccc}
\hline Condition & $\mathrm{v}_{\mathrm{s}}(\mathrm{m} / \mathrm{s})$ & $\mathrm{v}_{\mathrm{f}}(\mathrm{mm} / \mathrm{min})$ & $\mathrm{v}_{\mathrm{w}}(\mathrm{mm} / \mathrm{min})$ & Stock $(\mathrm{mm})$ & $\mathrm{s}_{\mathrm{t}}(\mathrm{mm} / \mathrm{rev})$ & $\mathrm{d}_{\mathrm{w}}(\mathrm{mm})$ & $\mathrm{v}_{\mathrm{t}}(\mathrm{mm} / \mathrm{min})$ \\
\hline Rough & 33 & 372 & 58 & 60 & 12 & 50 & 30 \\
Semi-finish & 33 & 372 & 58 & 30 & 12 & 50 & 30 \\
Finishing & 33 & 372 & 58 & 10 & 12 & 50 & 30 \\
\hline
\end{tabular}

where: $\mathrm{v}_{\mathrm{s}}$ : cutting speed; $\mathrm{v}_{\mathrm{f}}$ : radial velocity; $\mathrm{v}_{\mathrm{w}}$ : workpiece velocity; $\mathrm{s}_{\mathrm{t}}$ : crossfeed per revolution of the workpiece; $\mathrm{d}_{\mathrm{w}}$ : workpiece diameter; $\mathrm{v}_{\mathrm{t}}$ : transverse velocity. 
Specific cutting force for conventional wheel, rough grinding

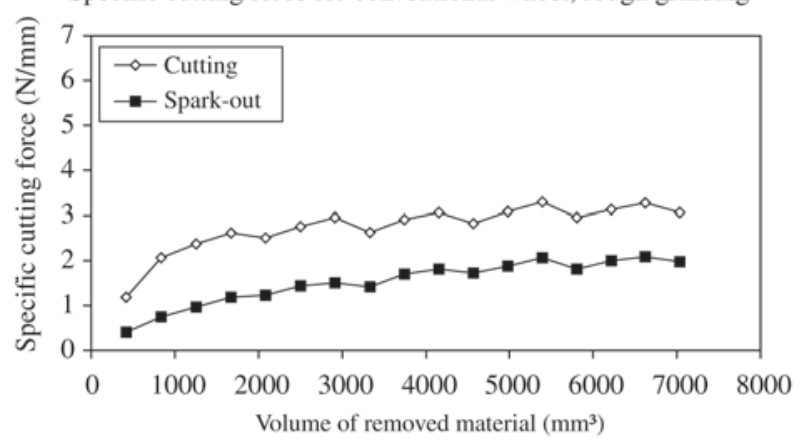

Figure 3. Cutting specific force for conventional wheel, in operation of high rough grinding.

Specific cutting force for conventional wheel, semi-finishing grinding

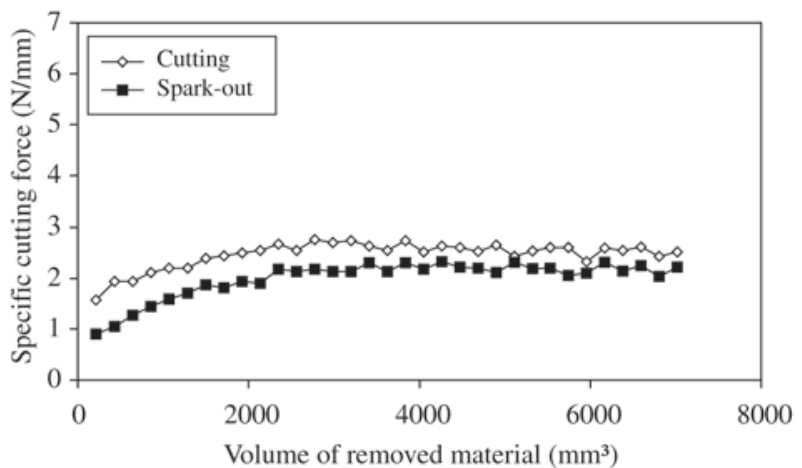

Figure 4. Cutting specific force for conventional wheel, in operation of rough grinding.

Specific cutting force for conventional wheel, finishing grinding

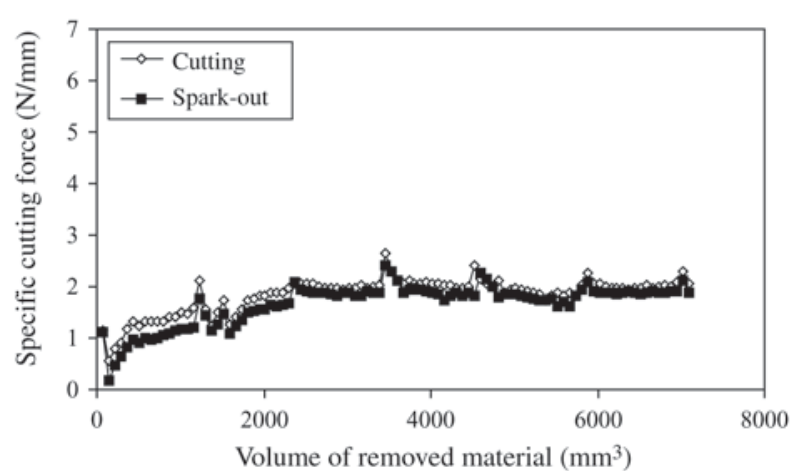

Figure 5. Cutting specific force for conventional wheel, in operation of finish grinding.
Specific cutting force for $\mathrm{CBN}$ wheel, rough grinding

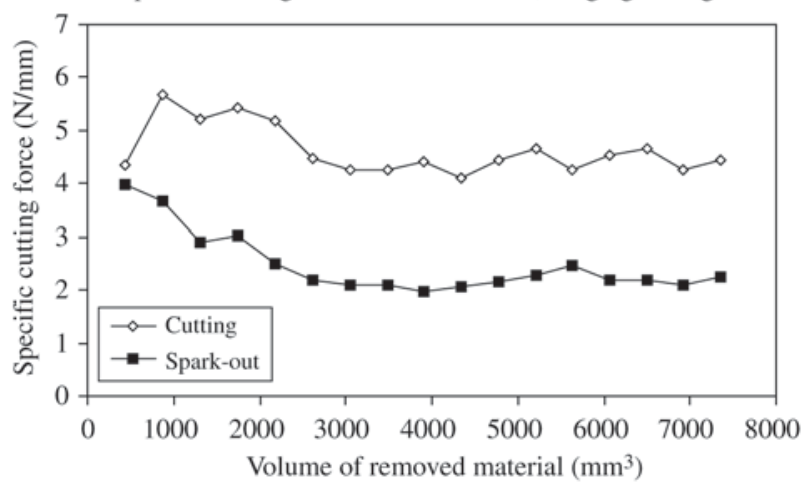

Figure 6. Cutting specific force for $\mathrm{CBN}$ wheel, in operation of high rough grinding.

Specific cutting force for $\mathrm{CBN}$ wheels, semi-finishing grinding

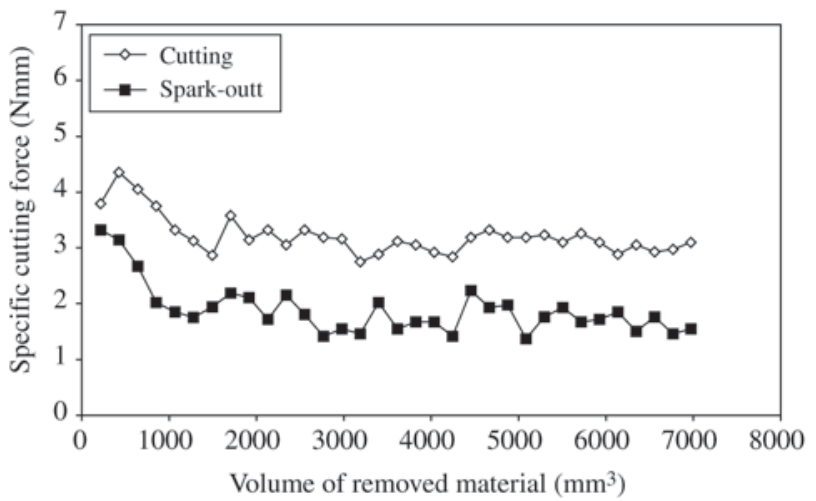

Figure 7. Cutting specific force for $\mathrm{CBN}$ wheel, in operation of rough grinding.

Specific cutting force for CBN wheels, finishing grinding

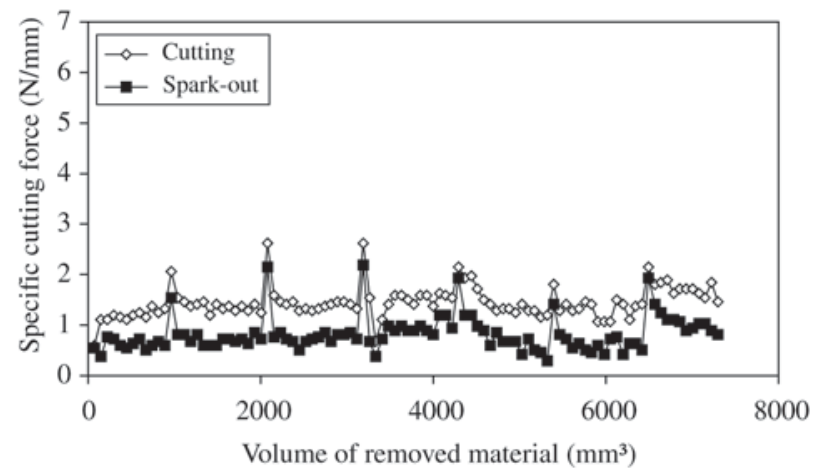

Figure 8. Cutting specific force for $\mathrm{CBN}$ wheel, in operation of finish grinding. 
increasing in the grinding forces for both wheels, which was already expected due to the increasing in the specific removed material.

In Figs. 3-8, it can be observed in the tests with the conventional wheel that there is a tendency in the cutting force to increase during the tests. One reason for this is the macroeffect action produced by dressing. Initially, the macroeffect caused by the dressing lead creates a sharper active surface in the wheel, which makes the cutting process easier, reducing the grinding forces. Although, when the cutting proceeds, the sharper grains are removed from the bond, remaining the under layer grains more numerous and less sharp. As these grains are more solidly bound to the bond, the abrasive grain itself suffers the wear produced by the attrition with the workpiece, increasing the force.

Another reason to that behavior of the tangential cutting force comes from the fact that few abrasive grains are removing material, due to the action of the dressing macroeffect, making them to wear and to get loose from the wheel-cutting surface. This makes the cutting force per grain to be high. Without the macroeffect, the dressing microeffect occurs, with many grains participating of the material removal. Consequently, the force per grain is lower but the total force is higher due to the dissipative losses of grains by generating heat, acoustic emission, attrition and scratching, among others.

In Figs. 6 to 8, the behavior of the cutting force for the superabrasive wheel is quite different from the conventional one. After a fast growing in the cutting force, there is a decrease in observed values. It can be associated to the concept of "active surface roughness".

The surface of any grinding wheel is significantly modified comparing to its bulk during the dressing operation. This process fractures and removes abrasive particles and bond to reduce the surface concentration of both. This affected layer, which is termed "active surface layer"can vary on depth from a few microns to over thirty (Yonekura and Yokogawa, 1983) ${ }^{6}$. For most medium and high stock removal applications (as observed in Figs. 7 and 6, respectively), once grinding begins the abrasive metals chips will wear the bond preferentially and further increase the affected depth. This is accompanied by a drop in grinding forces and a rise in the surface finish and is most striking for the first few parts after dressing. Compared to a vitrified $\mathrm{CBN}$ wheel, in which the dressing operation creates a round wheel concentric to its axis and preferentially removes the bond from around the abrasive grits, the resin bon $\mathrm{CBN}$ wheel tested has no inducted porosity and required a subsequent operation after truing to expose the abrasive grains. This operation termed "conditioning" creates this active surface roughness in the wheel surface which will be affected by the abrasive wear caused by the chips, which can preferentially erodes the bond, permit- ting a higher space to accommodates the generated chips, decreasing the forces.

In almost all the tests one can observe that the values of cutting force oscillate almost periodically. This is due to the removal of the workpiece from the machine for measuring its roughness and dimensional error. Every time the workpiece was repositioned in its place, some eccentricity made the force to increase some value, but it reached the stability after the defect was corrected.

\subsection{Results of roughness}

The surface roughness for each wheel is shown in the Figs. 9 and 10.

In the roughness results it can be observed that, for both wheels tested, increasing the grinding severity there is a decrease in the surface quality (increase the roughness values), due to the increase in the material removed rate.

Comparatively, the lower values of roughness were obtained when the conventional wheel were used, for all the

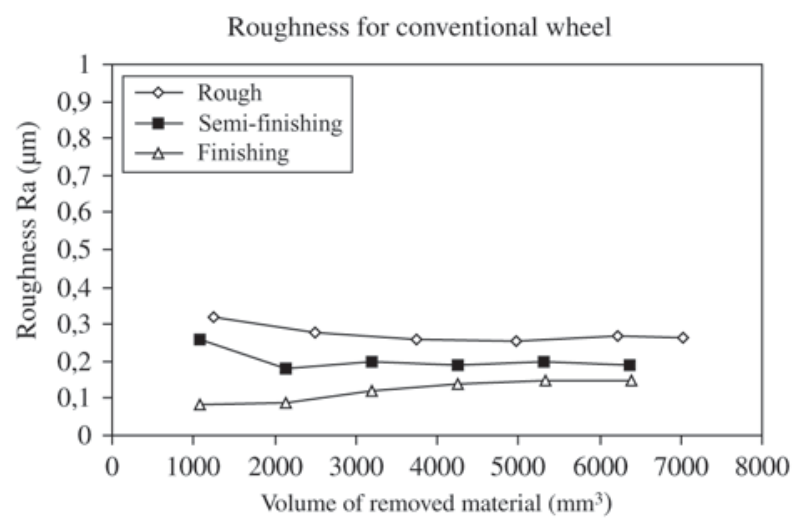

Figure 9. Roughness Ra for conventional wheel.

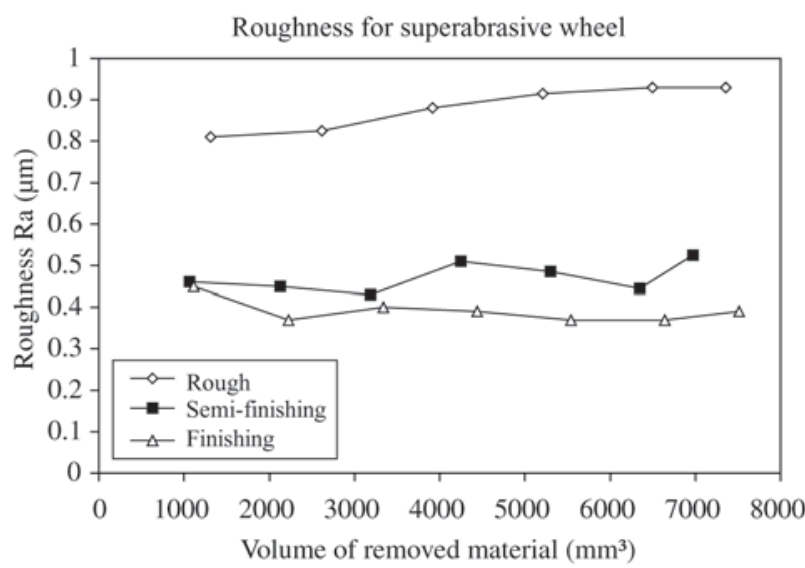

Figure 10. Roughness Ra for CBN superabrasive wheel. 


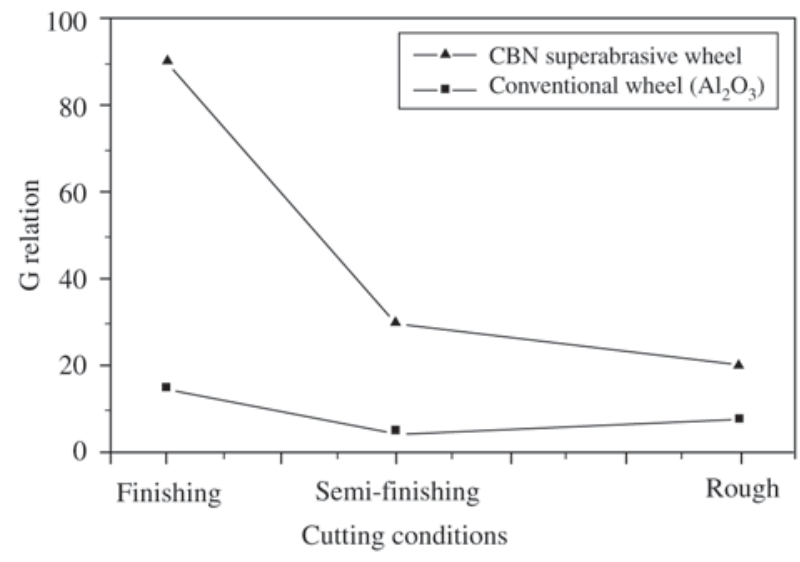

Figure 11. G relation for the conventional and superabrasive (CBN) wheel.

cutting conditions. The wheels tested presented almost the same grit size and concentration. Although, the dressing operation performed in the conventional wheel was more suitable. The single-point diamond dresser used combined with the appropriate dressing overlap ( $\mathrm{Ud}=1$ for the rough operation and $\mathrm{Ud}=5$ for finishing) permitted an appropriate sharpness in the wheel for the conditions tested. A distinct dressing condition was applied to the CBN grinding wheel. Using a rotary diamond disc, a speed ratio equal to 0.7 positive was applied, allowing a higher level of the crushing effect for the CBN wheel. This fact combined with the low level of induced porosity contributed to higher roughness values.

\subsection{Results of the G ratio}

The Fig. 11 shows the $\mathrm{G}$ relation values of each grinding wheel for the cutting conditions tested.

In Fig. 11, it can be observed that the $\mathrm{G}$ relation values for the superabrasive CBN wheel are greater than the ones observed for the conventional wheel. The lower wheel wear when using the $\mathrm{CBN}$ wheel was already expected due to the best mechanical proprieties of the CBN grains wheel compared to the conventional ones (higher Knoop hardness). Although, the observed values for the CBN wheel were lower than the expected ones (only twice greater than the conventional observed one). This fact can be attributed to the poor dressing applied to the CBN wheel, with a high level of crushing effect combined with an inappropriate and excessive conditioning. The not well-anchored grains can be easily removed from the bond as the grinding severity increases, leading to a higher wheel wear.

\section{Conclusions}

The authors concluded that:

- In the grinding operation tested, the conventional grinding wheel presented the lower values of cutting force for the rough and semi-finishing operations and the best roughness results due to the more suitable dressing operation performed when compared to the CBN one.

- Due to the best mechanical proprieties of its grains, the $\mathrm{CBN}$ wheel presented the higher $\mathrm{G}$ ratio values.

- In the tested conditions, the conventional wheel is the most appropriate grinding wheel to be used in the rough and semi-finishing and finishing operation, due to the best roughness and force results. In terms of $\mathrm{G}$ ratio, a cost analysis is crucial to determine if the differences observed among the wheels can justify the use of the CBN wheel. In a positive case, the dressing operation must be improved.

\section{Acknowledgments}

The authors want to express their gratitude and appreciation to FAPESP (Fundação de Amparo à Pesquisa do Estado de São Paulo), Mr. João Teixeira Vargas for his contribution in this work and the company MACOEX.

\section{References}

1. Bianchi, E.C.; "Ação da geometria teórica do cavaco no desgaste de rebolos de CBN com ligante resinóide". São Carlos, EESC - USP, 1992. Thesis, (Ph.D. in Mechanical Engineering).

2. Hitchiner, M.P., "Technological Advances in Creep Feed Grinding of Superalloys with CBN", $3^{\text {rd }}$ International Machining and Grinding Conference, SME, Cincinnati, Ohio, October 4-7, 1999

3. König, W.; Yegenoglu, K.; Stukenholz, B.; "Lower grinding costs and better workpiece quality by high-performance grinding with CBN whells". Aachen Technical University. Superabrasives'85, 22-25 de april de 1985, Chicago, Illinois. p. 9-21 a 9-43.

4. Malkin, S., 1989, "Grinding Geometry and Kinematics", In: Malkin, S. Grinding Technology: theory and applications of machining with abrasives. $1^{\mathrm{ed}}$ Chichester, Ellis Horwood Limited, c. 3, p. 45 a 79.

5. Tawakoli, S.T.; Tavakkoli, S.J.; "High efficiency deep grinding (HEDG) of Inconel and other materials". Wohlemberg. Superabrasives'85, 22-25 de april de 1985, Chicago, Illinois. p. 4-67 a 4-80.

6. Yonekura; Yokogawa, "Effects of "Tsukidashiryo" of Resin Bonded Borazon CBN Wheels on Grinding Performance". Bulletin of JSPE, v. 17, n. 2, p. 113-118, 1983. 